\title{
Risk Factors for Late-Onset Sepsis in Preterm Infants: A Multicenter Case-Control Study
}

\author{
Sofia el Manouni el Hassani ${ }^{a, b}$ Daniel J.C. Berkhout ${ }^{a, b}$
}

Hendrik J. Niemarkt ${ }^{c}$ Sarah Mann ${ }^{b}$ Willem P. de Boode ${ }^{d}$ Veerle Cossey ${ }^{e}$

Christian V. Hulzebos ${ }^{f}$ Anton H. van Kaam ${ }^{g, h}$ Boris W. Kramer ${ }^{\mathrm{i}}$

Richard A. van Lingen ${ }^{j} \quad$ Johannes B. van Goudoever ${ }^{k, I} \quad$ Daniel C. Vijlbrief ${ }^{m}$

Mirjam M. van Weissenbruch ${ }^{g}$ Marc A. Benninga ${ }^{a}$ Nanne K.H. de Boer ${ }^{n}$

Tim G.J. de Meij ${ }^{\text {b }}$

a Department of Pediatric Gastroenterology, Emma Children's Hospital, Amsterdam UMC, University of Amsterdam, Amsterdam, The Netherlands; ${ }^{b}$ Department of Pediatric Gastroenterology, Emma Children's Hospital, Amsterdam

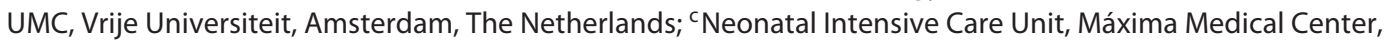
Veldhoven, The Netherlands; ${ }^{d}$ Amalia Children's Hospital, Radboud University Medical Center, Neonatal Intensive Care Unit, Radboud Institute for Health Sciences, Nijmegen, The Netherlands; ' Neonatal Intensive Care Unit, University Hospitals Leuven, Leuven, Belgium; ${ }^{f}$ Neonatal Intensive Care Unit, Beatrix Children's Hospital, University Medical Center, Groningen, The Netherlands; ${ }^{9}$ Neonatal Intensive Care Unit, Emma Children's Hospital, Amsterdam

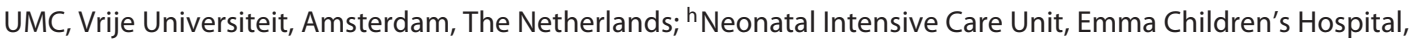
Amsterdam UMC, University of Amsterdam, Amsterdam, The Netherlands; 'Department of Pediatrics, Maastricht University Medical Center, Maastricht, The Netherlands; ${ }^{j}$ Neonatal Intensive Care Unit, Amalia Children's Centre, Isala, Zwolle, The Netherlands; ${ }^{k}$ Department of Pediatrics, Emma Children's Hospital, Amsterdam UMC, University of Amsterdam, Amsterdam, The Netherlands; 'Department of Pediatrics, Emma Children's Hospital, Amsterdam UMC, Vrije Universiteit, Amsterdam, The Netherlands; ${ }^{\mathrm{m}}$ Wilhelmina Children's Hospital, University Medical Center Utrecht, Neonatal Intensive Care Unit, Utrecht University, Utrecht, The Netherlands; ${ }^{n}$ Department of Gastroenterology and Hepatology, Amsterdam UMC, Vrije Universiteit, Amsterdam, The Netherlands

\section{Keywords}

Risk factors · Parenteral feeding · Breast feeding · Late-onset sepsis · Coagulase-negative staphylococcus

\footnotetext{
Abstract

Background: Late-onset sepsis (LOS) in preterm infants is a leading cause of mortality and morbidity. Timely recognition and initiation of antibiotics are important factors for improved outcomes. Identification of risk factors could allow selection of infants at an increased risk for LOS. Objectives:
}

The aim was to identify risk factors for LOS. Methods: In this multicenter case-control study, preterm infants born at $\leq 30$ weeks of gestation were included at 9 neonatal intensive care units. Detailed demographical and clinical data were collected daily up to day 28 postnatally. Clinical and demographic risk factors were identified using univariate and multivariate regression analyses in a 1:1 matched case-control cohort. Results: In total, 755 infants were included, including 194 LOS cases (41 gram-negative cases, 152 gram-positive cases, and 1 fungus). In the case-control cohort, every additional day of parenteral feeding increased the risk for LOS

\begin{tabular}{ll}
\hline KARGER & $\begin{array}{l}\text { () } 2019 \text { The Author(s) } \\
\text { Published by S. Karger AG, Basel Oper }\end{array}$ \\
E-Mail karger@karger.com & This article is licensed under the Creative Commons Attribution- \\
www.karger.com/neo & $\begin{array}{l}\text { NonCommercial-NoDerivatives 4.0 International License (CC BY- } \\
\text { NC-ND) (http://www.karger.com/Services/OpenAccessLicense). } \\
\text { Usage and distribution for commercial purposes as well as any dis- } \\
\text { tribution of modified material requires written permission. }\end{array}$
\end{tabular}

Sofia el Manouni el Hassani

Department of Pediatric Gastroenterology, Emma Children's Hospital

Amsterdam UMC, Vrije Universiteit, de Boelelaan 1117

NL-1081 HV Amsterdam (The Netherlands)

E-Mail s.elmanounielhassani@vumc.nl 
(adjusted $\mathrm{OR}=1.29 ; 95 \% \mathrm{Cl} 1.07-1.55 ; p=0.006$ ), whereas antibiotics administration decreased this risk $(\mathrm{OR}=0.08 ; 95 \%$ $\mathrm{Cl} 0.01-0.88 ; p=0.039$ ). These findings could largely be attributed to specific LOS-causative pathogens, since these predictive factors could be identified for gram-positive, but not for gram-negative, LOS cases. Specifically cephalosporins administration prior to clinical onset was inversely related to coagulase-negative staphylococcus LOS (CoNSLOS) development. Formula feeding was an independent risk factor for development of CoNS-LOS (OR $=3.779 ; 95 \% \mathrm{Cl}$ $1.257-11.363 ; p=0.018)$. Conclusion: The length of parenteral feeding was associated with LOS, whereas breastmilk administration was protective against CoNS-LOS. A rapid advancement of enteral feeding, preferably with breastmilk, may proportionally reduce the number of parenteral feeding days and consequently the risk for LOS.

C 2019 The Author(s)
Published by S. Karger AG, Basel

\section{Introduction}

Late-onset sepsis (LOS), defined as sepsis onset after $72 \mathrm{~h}$ of life, is a leading cause of mortality in the neonatal intensive care unit (NICU) [1]. The incidence rates for LOS in preterm infants vary between 20 and $38 \%$ in the first 120 days of life, and mortality rates range from 13 to $19 \%$ [1-4]. Survivors are at risk for prolonged hospitalization, development of necrotizing enterocolitis (NEC), bronchopulmonary dysplasia, and neurodevelopmental impairment $[1,2,5]$. The diagnosis of LOS in daily clinical practice may be challenging, especially in preterm infants, as clinical symptoms have limited sensitivity and specificity. The gold standard for diagnosis is confirmation of a pathogen in the blood culture, which is limited by suboptimal sensitivity and delay of a definite diagnosis because of the turnaround time to become positive [6]. In addition, screening of bodily fluids (e.g., blood and urine) may also require an invasive procedure, increasing the risk for LOS independently [6]. Several studies have identified risk factors for LOS, including a lower birth weight, gestational age (GA), and the presence of central venous catheters $[1,3,7]$. In addition, breastmilk feeding within the first month of life has been shown to be protective against LOS development [8]. However, most of these studies are characterized by a small number of cases, retrospective and single-center study designs, and the absence of detailed (daily) clinical data, limiting the possibility of adequate matching with controls and thus the ability to draw firm conclusions. Identification of independent risk factors for LOS in preterm infants may allow selection of in- fants at an increased risk and the development of novel, personalized therapeutic strategies aimed at reducing the LOS incidence. Therefore, we aimed to identify independent risk factors contributing to the development of LOS in preterm born infants in a multicenter case-control study with an overview of the clinical characteristics of patients with LOS within the first month of life.

\section{Materials and Methods}

\section{Patients and Data Collection}

This case-control study was conducted between October 2014 and January 2017 at 2 level II and 7 level III NICU situated in The Netherlands and Belgium (online suppl. Table 1; for all online suppl. material, see www.karger.com/doi/10.1159/000497781). None of the participating centers administered probiotics routinely. The current study was nested in an ongoing study on the identification of early diagnostic biomarkers for NEC and LOS [9]. In that study, fecal samples and clinical data were collected (if applicable on a daily base) from infants born at a GA $\leq 30$ weeks, up to 28 days' postnatal age (Table 1). In order to identify factors associated with LOS development the variables were assessed prior to clinical onset in the matched case-control cohort. In case of transfer from the NICU to a referral hospital or death prior to 28 days' postnatal age, data collection was ceased.

\section{Matching Procedure}

From this original cohort, infants diagnosed with LOS were strictly matched to 1 healthy control infant based on GA ( \pm 3 days), birthweight ( $\pm 10 \mathrm{~g})$, and postnatal age at LOS onset ( \pm 0 days). Infants who developed LOS as defined below were included as cases, and infants who did not develop LOS were included as controls. Both cases and controls were excluded in case of early-onset sepsis (positive blood cultures $<72 \mathrm{~h}$ postnatally) or in case of NEC ( $\geq$ Bell's stage $2 \mathrm{~A}$ ) or SIP during the follow-up period and an incomplete or missing medical file.

\section{Definitions}

LOS cases were defined as infants with a pathogen isolated from the blood culture drawn $\geq 72 \mathrm{~h}$ postnatally and pathogenbased antibiotic treatment was continued for $\geq 5$ days, according to Vermont Oxford criteria [10]. Only the first LOS episode was included in the analysis. Isolated pathogens from blood cultures were classified into 4 categories: gram-positive bacteria, gram-negative bacteria, fungi, and coagulase-negative staphylococci (CoNS). A CoNS-positive culture was considered a CoNS-LOS when a CRP level $\geq 10 \mathrm{mg} / \mathrm{L}$ was measured within $72 \mathrm{~h}$ of LOS onset. When $\geq 2$ pathogens were isolated from the blood culture (one being CoNS), the presence of CoNS was considered as contamination. Remaining definitions of collected data are described in Table 1.

\section{Statistical Analysis}

Statistical Package for the Social Science (SPSS) version 22.0 (IBM, Armonk, NY, USA) was used for the statistical analysis. First, during the entire inclusion period of 28 days, collected demographic and clinical variables from all infants with LOS were compared with non-LOS cases. Potential associations between as- 
Table 1. Collected variables and definitions

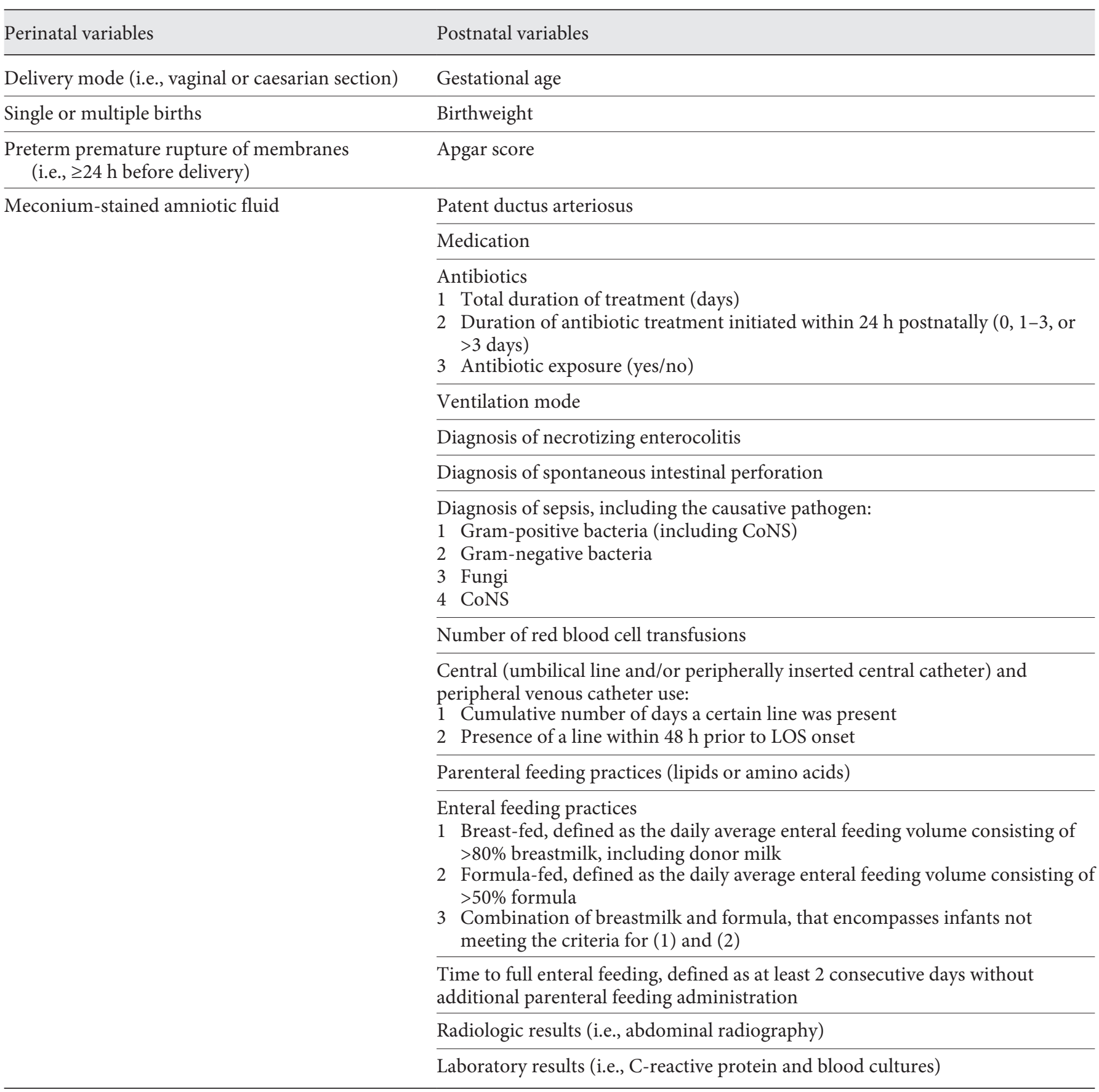

sessed variables and the development of LOS were identified via univariate logistic regression analysis.

Secondly, in the strictly 1:1 matched case-control cohort univariate logistic regression analysis was performed on clinical and demographical variables in the period preceding the day of LOS onset. Subsequently, independent risk factors were identified via multivariable regression analysis. This model was constructed using the backward likelihood ratio method, ultimately including statistically significant variables ( $p$ value $<0.05$ ). Variables included in this model were selected based on their two-tailed $p$ value calculated from the univariate regression analyses. Only variables with a $p$ value $\leq 0.30$ were included. For every 10 cases one variable was included in the multivariable regression analysis. Results were considered statistically significant for $p$ values $\leq 0.05$.

Thirdly, potential predictive factors were assessed for the 3 subgroups via univariate logistic regression. In addition, independent 
Table 2. Characteristics of LOS infants and matched controls in the period preceding LOS diagnosis $\left(\mathrm{T}_{0}\right)$

\begin{tabular}{|c|c|c|c|c|c|c|}
\hline & $\begin{array}{l}\text { LOS } \\
(n=194)\end{array}$ & $\begin{array}{l}\text { Non-LOS } \\
(n=194)\end{array}$ & Univariate analysis $^{1}$ & $\begin{array}{l}p \\
\text { value }\end{array}$ & $\begin{array}{l}\text { Multivariate } \\
\text { analysis }^{1}\end{array}$ & $\begin{array}{l}p \\
\text { value }\end{array}$ \\
\hline Median gestational age (IQR), weeks+days & $27+1(25+5-28+5)$ & $27+1(25+5-28+5)$ & $1.000(0.984-1.017)$ & 0.980 & & \\
\hline Mean birth weight $( \pm S D), g$ & $965.85 \pm 280.21$ & $966.64 \pm 273.71$ & $1.000(0.999-1.001)$ & 0.978 & & \\
\hline Gender, male, $n$ (\%) & $106(54.9)$ & $97(50.3)$ & $1.206(0.808-1.799)$ & 0.359 & & \\
\hline Vaginal delivery, $n(\%)$ & $89(46.1)$ & $99(51.3)$ & $1.078(0.722-1.609)$ & 0.715 & & \\
\hline Multiple births, $n(\%)$ & $74(38.3)$ & $65(33.7)$ & $1.208(0.796-1.833)$ & 0.375 & & \\
\hline PPROM, $n(\%)$ & $46(23.8)$ & $47(24.4)$ & $0.999(0.626-1.595)$ & 0.998 & & \\
\hline Meconium amniotic fluid, $n(\%)$ & $4(2.1)$ & $4(2.1)$ & $1.011(0.249-4.106)$ & 0.988 & & \\
\hline Median 1-min Apgar score (IQR) & $5(3-7)$ & $6(3-7)$ & $0.991(0.909-1.081)$ & 0.839 & & \\
\hline Median 5-min Apgar score (IQR) & $7(6-8)$ & $7(6-8)$ & $0.982(0.872-1.105)$ & 0.759 & & \\
\hline PDA, $n(\%)$ & $76(39.4)$ & $62(32.1)$ & $1.430(0.617-3.315)$ & 0.404 & & \\
\hline \multicolumn{7}{|l|}{ PDA treatment type, $n(\%)$} \\
\hline Ibuprofen & $70(36.3)$ & $59(30.6)$ & Reference & 0.840 & & \\
\hline Indomethacin & $4(5.4)$ & $2(3.2)$ & $1.686(0.298-9.531)$ & 0.555 & & \\
\hline Surgical & 0 & $1(1.6)$ & NA & 1.000 & & \\
\hline Central line exposure, $n(\%)$ & $149(77.2)$ & $161(83.4)$ & $0.673(0.405-1.117)$ & 0.126 & & \\
\hline Median central line time (IQR), days & $8(6-10)$ & $7(5-10)$ & $1.028(0.963-1.097)$ & 0.403 & & \\
\hline Central line exposure $48 \mathrm{~h}$ prior $\mathrm{T}_{0}, n(\%)$ & $111(57.5)$ & $118(61.1)$ & $0.860(0.573-1.292)$ & 0.468 & & \\
\hline Peripheral line exposure, $n(\%)$ & $186(96.4)$ & $187(96.9)$ & $0.853(0.281-2.585)$ & 0.778 & & \\
\hline Median peripheral line time (IQR), days & $7(4-10)$ & $7(4-9)$ & $1.006(0.961-1.054)$ & 0.790 & & \\
\hline Peripheral line exposure $48 \mathrm{~h}$ prior $\mathrm{T}_{0}, n(\%)$ & $154(79.8)$ & $141(73.1)$ & $1.456(0.907-2.339)$ & 0.120 & $1.693(0.943-3.043)$ & 0.078 \\
\hline Median RBC transfusion time (IQR), days & $2(1-2)$ & $2(1-2)$ & $1.097(0.871-1.382)$ & 0.432 & & \\
\hline Invasive ventilation exposure, $n(\%)$ & $103(53.4)$ & $107(55.4)$ & $0.920(0.616-1.373)$ & 0.683 & & \\
\hline Median invasive ventilation time (IQR), days & $4(2-9)$ & $5(2-9)$ & $1.000(0.947-1.056)$ & 0.996 & & \\
\hline Noninvasive ventilation exposure, $n(\%)$ & $175(90.7)$ & $166(86.0)$ & $1.581(0.840-2.978)$ & 0.156 & & \\
\hline Median noninvasive ventilation time (IQR), days & $7(4-9)$ & $6(4-10)$ & $0.996(0.955-1.040)$ & 0.870 & & \\
\hline \multicolumn{7}{|l|}{ Enteral feeding type, $n(\%)$} \\
\hline Breast milk & $80(41.5)$ & $77(39.9)$ & Reference & 0.716 & & \\
\hline Formula milk & $49(25.4)$ & $41(21.2)$ & $1.150(0.684-1.934)$ & 0.597 & & \\
\hline Combination & $56(29.0)$ & $59(30.6)$ & $0.914(0.565-1.478)$ & 0.713 & & \\
\hline Achieved full enteral feeding, $n$ (\%) & $27(14)$ & $36(18.7)$ & $0.854(0.482-1.511)$ & 0.587 & & \\
\hline Median total of parental feeding time (IQR), days & $9(7-11)$ & $8(6-10)$ & $1.095(1.018-1.177)$ & $0.014^{*}$ & $1.125(1.041-1.216)$ & $0.003^{*}$ \\
\hline \multicolumn{7}{|l|}{ Total time from birth (days), $n$ (\%) } \\
\hline $0-5$ & $20(10.4)$ & $34(17.6)$ & Reference & 0.090 & & \\
\hline $5-10$ & $53(27.5)$ & $68(35.2)$ & $1.325(0.686-2.561)$ & 0.402 & & \\
\hline$>10$ & $55(28.5)$ & $46(23.8)$ & $2.033(1.033-4.000)$ & $0.040^{*}$ & & \\
\hline \multicolumn{7}{|l|}{ Medication, $n(\%)$} \\
\hline Inotropes & $11(5.7)$ & $19(9.8)$ & $0.341(0.116-1.001)$ & 0.050 & & \\
\hline Antimycotics & $9(4.7)$ & $11(5.7)$ & $0.491(0.158-1.527)$ & 0.219 & & \\
\hline \multicolumn{7}{|l|}{ Postpartum antibiotic administration (days), $n$ (\%) } \\
\hline None & $27(14.0)$ & $28(14.5)$ & Reference & 0.872 & & \\
\hline $1-3$ & $111(57.5)$ & $106(54.9)$ & $1.086(0.601-1.963)$ & 0.785 & & \\
\hline$>3$ & $55(28.5)$ & $59(30.6)$ & $0.967(0.508-1.840)$ & 0.918 & & \\
\hline Antibiotic exposure (yes), $n$ (\%) & $176(91.2)$ & $184(95.3)$ & $0.506(0.220-1.166)$ & 0.110 & & \\
\hline Median antibiotic time (IQR), days & $4(3-6)$ & $3(2-6)$ & $1.027(0.956-1.103)$ & 0.469 & & \\
\hline \multicolumn{7}{|l|}{ Antibiotic exposure per group, $n(\%)$} \\
\hline Aminoglycoside & $150(77.7)$ & $152(78.8)$ & $1.177(0.667-2.076)$ & 0.575 & & \\
\hline Carbapenem & $2(1.0)$ & $6(3.1)$ & $0.339(0.068-1.703)$ & 0.189 & $0.257(0.048-1.386)$ & 0.114 \\
\hline Cephalosporin & $32(16.6)$ & $52(26.9)$ & $0.560(0.340-0.923)$ & $0.023^{*}$ & $0.562(0.320-0.987)$ & $0.045^{*}$ \\
\hline Glycopeptide & $21(10.9)$ & $26(13.5)$ & $0.818(0.442-1.515)$ & 0.523 & & \\
\hline Macrolides & $2(1.0)$ & $4(2.1)$ & $0.514(0.093-2.844)$ & 0.446 & & \\
\hline Oxazolidinones & 0 & 0 & NA & NA & & \\
\hline Penicillin (-clavulanic acid) & $170(88.1)$ & $177(91.7)$ & $0.960(0.304-3.036)$ & 0.945 & & \\
\hline Quinolones & 0 & 0 & NA & $\mathrm{NA}$ & & \\
\hline Rifampicin & 0 & 0 & $\mathrm{NA}$ & $\mathrm{NA}$ & & \\
\hline Trimethoprim-sulfamethoxazole & $1(0.5)$ & 0 & NA & NA & & \\
\hline Mortality, $n(\%)$ & $13(6.7)$ & $3(1.6)$ & $4.574(1.282-16.317)$ & $0.019^{*}$ & & \\
\hline Median age at death (IQR), days & $17(10-21)$ & $13(10-13)$ & $1.097(0.869-1.383)$ & 0.437 & & \\
\hline Discharge before 28 days, $n(\%)$ & $50(25.9)$ & $54(28.0)$ & $0.900(0.574-1.411)$ & 0.646 & & \\
\hline Median age at discharge (IQR), days & $18(13-21)$ & $18(12-21)$ & $0.996(0.928-1.068)$ & 0.905 & & \\
\hline
\end{tabular}

LOS, late-onset sepsis; NA, not applicable; $\mathrm{T}_{0}$, clinical onset of sepsis; PPROM, preterm premature rupture of membranes; PDA, patent ductus arteriosus; RBC, red blood cells. ${ }^{1}$ Values are presented as OR (95\% CI). * Statistically significant difference.

risk factors were identified using multivariable logistic regression models. This model was constructed using the forward likelihood ratio method, considering the smaller sample size, ultimately including statistically significant variables $(p$ value $<0.10)$. Other statistical settings remained the same as described for the total matched case-control cohort.

All results are displayed as (unadjusted) OR with corresponding $95 \% \mathrm{CI}$ and $p$ values.

\section{Results}

In total, 755 infants were included in the analysis, constituting 194 LOS cases (23\%). The demographic and clinical characteristics of the LOS cases and controls in the overall cohort are depicted in online supplementary Table 2. Further clarification of the LOS incidence, the causative pathogen distribution, and the median age 
of onset are provided in online supplementary Tables 3 and 4 .

Table 2 provides an overview of the demographics and characteristics of the LOS cases versus the matched controls (1:1) irrespectively of the causative pathogen. Duration of parenteral feeding was identified as an independent risk factor for LOS development irrespectively of the causative pathogen $(\mathrm{OR}=1.125 ; 95 \% 1.041-1.216 ; p=$ 0.003). Third-generation cephalosporins administration was identified as an independent factor inversely associated with LOS development $(\mathrm{OR}=0.562$; 95\% CI 0.320 $0.987 ; p=0.045$ ). Remaining variables showed no significant differences.

\section{Gram-Negative Bacteria}

No differences in clinical and demographic characteristics were found between gram-negative LOS cases and controls prior to LOS onset. However, a higher mortality rate was observed in LOS cases (unadjusted $\mathrm{OR}=11.400$; 95\% CI 1.367-95.043; $p=0.025$ ) (Table 3).

\section{Gram-Positive Bacteria}

Duration of parenteral feeding (days) was identified as an independent risk factor for Gram-positive LOS (OR = 1.289; 95\% CI 1.074-1.547; $p=0.006$ ). Antibiotics exposure prior to clinical onset was inversely related to LOS development $(\mathrm{OR}=0.078 ; 95 \%$ CI $0.007-0.879 ; p=$ $0.039)$. Remaining variables showed no significant differences (Table 4).

\section{Coagulase-Negative Staphylococcus}

The total number of days of peripheral line exposure $(\mathrm{OR}=1.238 ; 95 \% \mathrm{CI} 1.086-1.411 ; p=0.001)$ and formula feeding $(\mathrm{OR}=3.779 ; 95 \%$ CI $1.257-11.363, p=0.018)$ preceding clinical onset were identified as independent risk factors for CoNS-LOS. Administration of third-generation cephalosporins was found to be an independent factor inversely associated with CoNS-LOS $(\mathrm{OR}=0.229$; $95 \%$ CI $0.086-0.612 ; p=0.003$ ). There were no significant differences regarding the remaining variables between the 2 subgroups (Table 5).

\section{Discussion}

This case-control study aimed at identifying demographic and clinical risk factors associated with the development of LOS in preterm infants in a multicenter setting. We demonstrated that every additional day of parenteral feeding was associated with an increased risk of
LOS development. Third-generation cephalosporins administration was identified as an independent factor inversely associated with the development of CONS-LOS, whereas formula feeding was associated with an increased risk.

In a previous study, formula-fed infants showed increased odds for CoNS-LOS development compared to breast-fed infants [11], and this was confirmed in the current study. Breast milk might be protective due to its antiinfective, microbiome-modulating, and immune-stimulatory properties [12]. Several studies have demonstrated that infants who receive breastmilk are more likely to achieve full enteral feeding at an earlier stage compared to formula-fed infants, resulting in earlier cessation of parenteral feeding $[1,4,13]$. We demonstrated that exposure to parenteral feeding for more than 10 consecutive days was associated with an increased risk of LOS development. It could be debated whether clinicians should aim to limit the exposure to parenteral feeding to no longer than 10 days by a more rapid advancement of enteral feeding with preferably breastmilk to reduce the risk of LOS development. On the contrary, a rapid advancement of enteral feeding might increase the risk for NEC development. However, studies have shown that rapid advancement of the enteral feeding volume within the first week of life is not significantly associated with NEC in preterm and very low birthweight infants $[14,15]$.

In this study, exposure to antibiotics was associated with decreased odds for the development of gram-positive LOS, irrespectively of the type and duration of antibiotics. Cephalosporin exposure was associated with a decreased risk for CoNS-LOS, possibly due to the sensitivity of CoNS species to cephalosporins. Therefore, exposure to this agent could reduce the risk of invasion of CoNS from either the skin or the gut into the bloodstream $[16,17]$. However, implementation of routine administration of cephalosporins in preterm infants remains a topic of debate mainly because of the increased riskfor colonization with extended-spectrum $\beta$-lactamase producing bacteria [18]. The observed protective effects of early exposure to specific antibiotics against the development of LOS indicate that the microbiota may be involved in the pathophysiology of at least a selection of LOS cases. The influence of early microbiota colonization and alterations in microbiota composition in LOS pathophysiology has been considered in several studies $[19,20]$. This phenomenon might lead to the development of strategies aimed at early manipulation of the microbiota to prevent LOS development, for example by administration of probiotics instead of antibiotic pro- el Manouni el Hassani et al. 
Table 3. Characteristics of LOS infants caused by gram-negative bacteria and matched controls in the period preceding LOS diagnosis $\left(\mathrm{T}_{0}\right)$

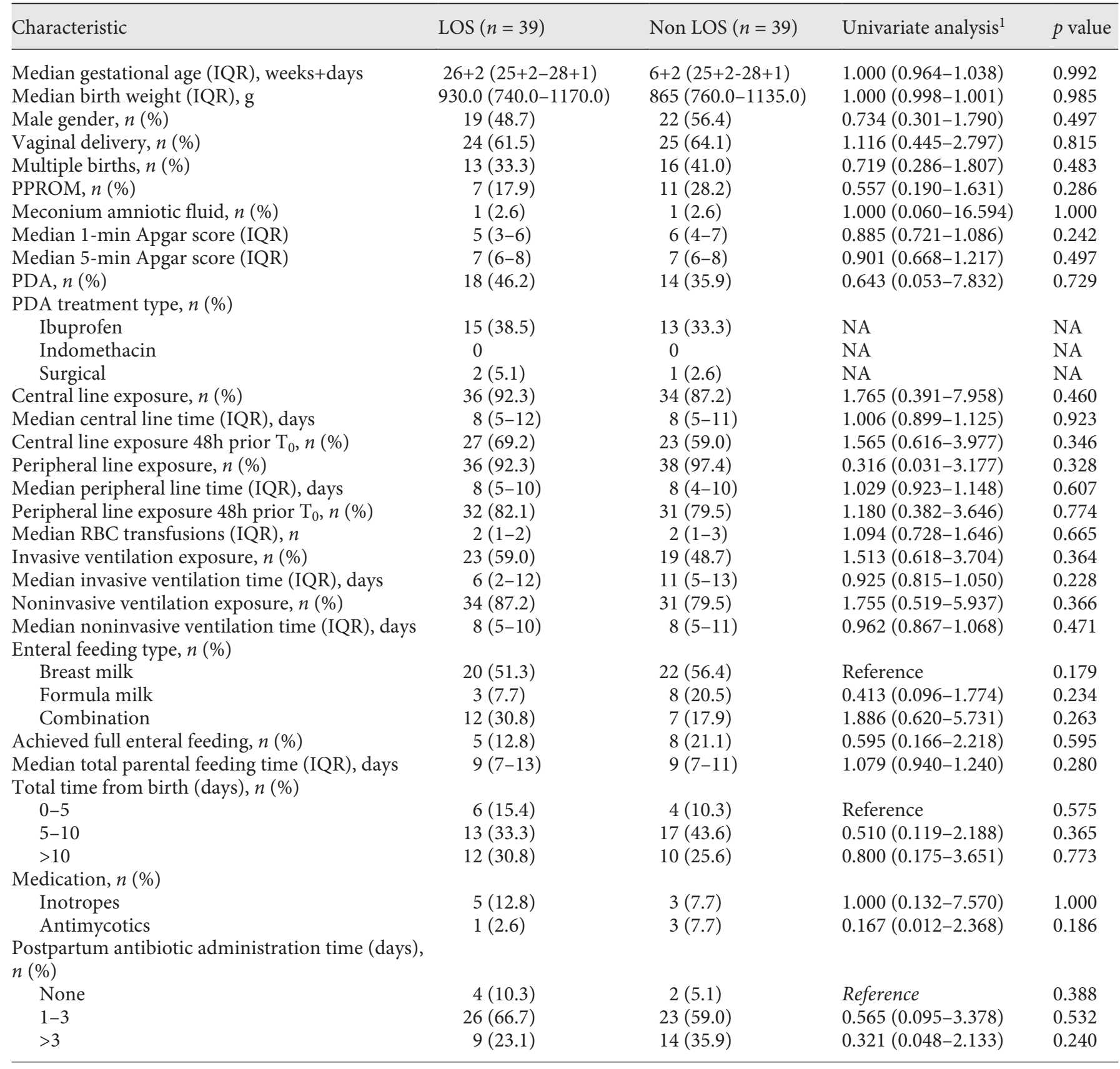

phylaxis, reducing the risk for colonization with multiresistant pathogens [21]. It has been demonstrated that probiotic supplementation significantly reduced the risk of LOS in preterm infants $(n=9,416)$ [22]. However, additional studies are needed to evaluate the optimal dosage, duration, and identification of the best suitable bacterial strains for supplementation.
Previous studies have demonstrated an association between (the duration of) central line exposure and the development of LOS in preterm infants $[1,7,23]$. Line exposure significantly increased the risk of gram-positive bacteria-related LOS in preterm infants, especially CoNSLOS. This increased risk may be caused by contaminated intravenous fluids or catheter hubs (intraluminal con- 
Table 3 (continued)

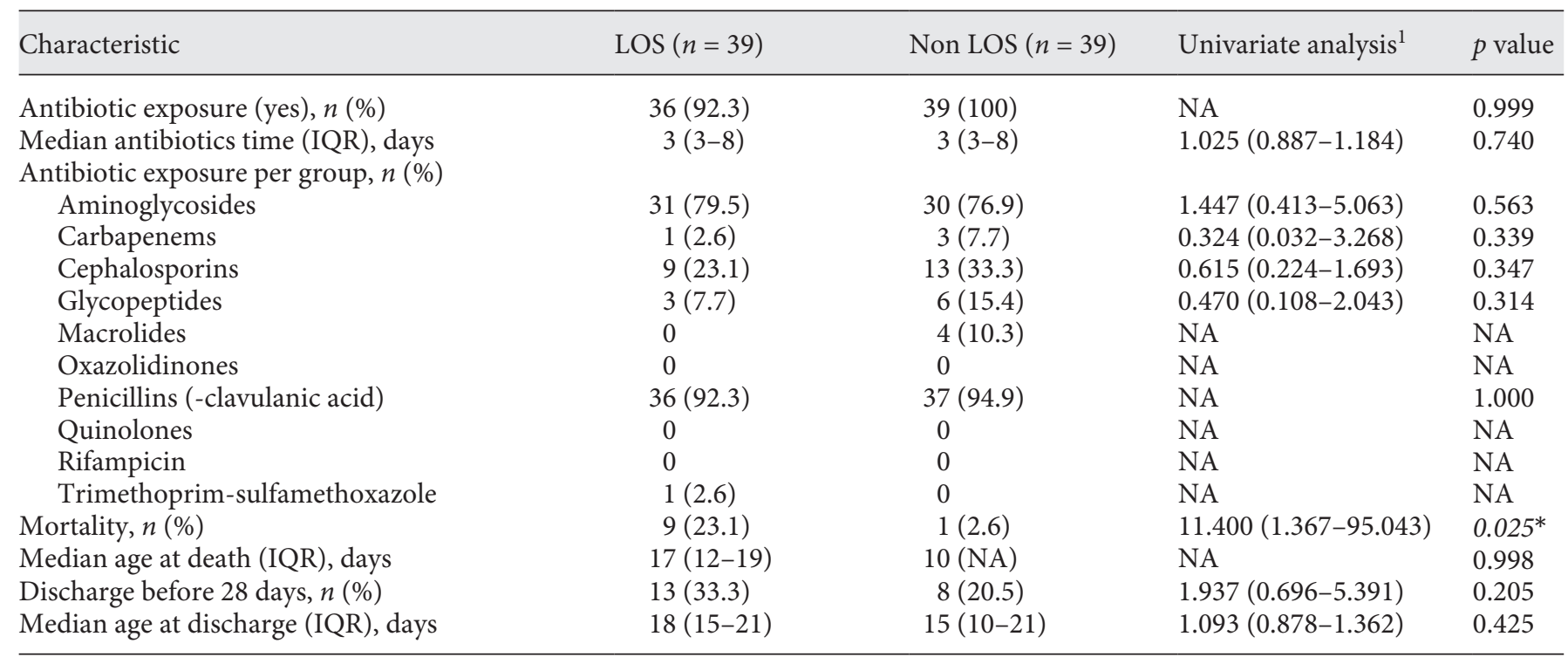

LOS, late-onset sepsis; NA, not applicable; $\mathrm{T}_{0}$, clinical onset of sepsis; PPROM, preterm premature rupture of membranes; PDA, patent ductus arteriosus; RBC, red blood cells. ${ }^{1}$ Values are presented as OR (95\% CI). * Statistically significant difference.

tamination) or by skin-colonizing organisms invading the bloodstream via the catheter track (extraluminal contamination) [24]. We observed that every additional day that a peripheral line was present the risk of CoNS-LOS increased, while central line exposure (presence/absence and duration) was not an independent risk factor for CoNS-LOS. The apparent discrepancy in the study results might be explained by differences in study design. The majority of preterm infants have either a central or a peripheral line during the first month of life, and a younger GA is associated with an increased risk for LOS $[1,7]$. In the current study we matched study participants on GA to prevent bias by this age-related catheter exposure. A positive association between the dwell time of peripheral catheters and central venous lines and LOS development has been described in several studies, although the results are contradictory $[23,25,26]$. We found no association between the dwell time of both central and peripheral catheters and LOS. We hypothesized that an increased risk of LOS development is not merely influenced by the dwell time of either central or peripheral lines but predominantly by frequent replacement of central and/or peripheral catheters. This may increase the risk of insertion of potential causative pathogens by contaminated catheter hubs or by creation of new entrance sites $[25,26]$. However, this variable was not taken into account in the present study.
This study has several strengths; detailed data collection in a multicenter design allowed for a strictly matched case-control comparison and the relatively large sample size allowed to determination of predictive factors per subgroup of causative pathogens. This study has also several limitations that need to be addressed. First, data collection was limited to the first 28 days postnatally, which might have resulted in a lower LOS incidence and mortality rate. Hypothetically, limiting data collection until a postnatal age of 28 days might also result in allocation of infants into the control group while they might have developed sepsis after the defined follow-up period, therefore possibly resulting in an underestimation of the potential risk factors. Secondly, this study contained limited obstetric data. This could hypothetically have influenced the outcome, since maternal factors may also include risk factors for LOS as they have been described to influence the neonatal immune system. Thirdly, center-specific effects could not be excluded from the analyses due to variating LOS incidences, limiting centerbased matching. However, this could allow for identification of factors leading to an increased risk for LOS development as a result of local protocols used. Lastly, prolonged parenteral nutrition could also be seen as an early sign of LOS, particularly in less-fulminant CoNSLOS, rather than a preonset risk factor. However, the relatively large number of LOS cases allowed us to focus on
48

Neonatology 2019;116:42-51 DOI: $10.1159 / 000497781$ el Manouni el Hassani et al. 
Table 4. Characteristics of LOS infants caused by gram-positive bacteria and matched controls in the period preceding LOS diagnosis $\left(\mathrm{T}_{0}\right)$

\begin{tabular}{|c|c|c|c|c|c|c|}
\hline & $\operatorname{LOS}(n=152)$ & Non-LOS $(n=152)$ & Univariate analysis $^{1}$ & $\begin{array}{l}p \\
\text { value }\end{array}$ & $\begin{array}{l}\text { Multivariate } \\
\text { analysis }^{1}\end{array}$ & $\begin{array}{l}p \\
\text { value }\end{array}$ \\
\hline Median gestational age (IQR), weeks+days & $27+4(25+6-28+5)$ & $27+4(25+6-28+5)$ & $1.000(0.981-1.020)$ & 0.981 & & \\
\hline Mean birth weight $( \pm S D), g$ & $965.8(274.7)$ & $968.0(273.3)$ & $1.000(0.999-1.001)$ & 0.944 & & \\
\hline Male gender, $n(\%)$ & $85(55.9)$ & $74(48.7)$ & $1.337(0.852-2.100)$ & 0.207 & & \\
\hline Vaginal delivery, $n(\%)$ & $64(42.1)$ & $84(55.3)$ & $1.075(0.682-1.695)$ & 0.755 & & \\
\hline Multiple births, $n(\%)$ & $60(39.5)$ & $48(31.5)$ & $1.413(0.881-2.265)$ & 0.151 & & \\
\hline PPROM, $n(\%)$ & $39(25.7)$ & $35(23.0)$ & $1.197(0.707-2.026)$ & 0.503 & & \\
\hline Meconium amniotic fluid, $n(\%)$ & $3(2.0)$ & $2(1.3)$ & $1.521(0.250-9.242)$ & 0.649 & & \\
\hline Median 1-min Apgar score (IQR) & $6(3-7)$ & $5(3-7)$ & $1.011(0.917-1.114)$ & 0.827 & & \\
\hline Median 5-min Apgar score (IQR) & $7(6-9)$ & $7(7-8)$ & $0.991(0.870-1.129)$ & 0.890 & & \\
\hline $\mathrm{PDA}, n(\%)$ & $66(43.4)$ & $59(38.8)$ & $1.206(0.740-1.966)$ & 0.453 & & \\
\hline \multicolumn{7}{|l|}{ PDA treatment type, $n(\%)$} \\
\hline Ibuprofen & $54(35.5)$ & $45(29.6)$ & Reference & 0.919 & & \\
\hline Indomethacin & 0 & $1(0.7)$ & NA & 1.000 & & \\
\hline Surgical & $2(1.3)$ & $1(0.7)$ & $1.667(0.146-18.985)$ & 0.681 & & \\
\hline Central line exposure, $n(\%)$ & $111(73)$ & $125(82.2)$ & $0.585(0.338-1.012)$ & 0.055 & & \\
\hline Median central line time (IQR), days & $8(6-9)$ & $7(5-10)$ & $1.034(0.953-1.121)$ & 0.420 & & \\
\hline Central line exposure $48 \mathrm{~h}$ prior $\mathrm{T}_{0}, n(\%)$ & $83(54.6)$ & $94(61.8)$ & $0.742(0.470-1.172)$ & 0.201 & & \\
\hline Peripheral line exposure, $n(\%)$ & $148(97.4)$ & $147(96.7)$ & $1.259(0.331-4.780)$ & 0.736 & & \\
\hline Median peripheral line time (IQR), days & $7(4-10)$ & $7(4-9)$ & $1.006(0.955-1.060)$ & 0.812 & & \\
\hline Peripheral line exposure $48 \mathrm{~h}$ prior $\mathrm{T}_{0}, n(\%)$ & $120(78.9)$ & $108(71.1)$ & $1.528(0.904-2.581)$ & 0.113 & & \\
\hline Median RBC transfusions (IQR), $n$ & $2(1-2)$ & $2(1-2)$ & $1.091(0.823-1.444)$ & 0.545 & & \\
\hline Invasive ventilation exposure, $n(\%)$ & $26(17.1)$ & $38(25.0)$ & $2.098(0.974-4.519)$ & 0.058 & & \\
\hline Median invasive ventilation time (IQR), days & $4(2-9)$ & $5(2-9)$ & $1.011(0.949-1.076)$ & 0.740 & & \\
\hline Noninvasive ventilation exposure, $n(\%)$ & $139(91.4)$ & $133(87.5)$ & $1.527(0.726-3.216)$ & 0.265 & & \\
\hline Median noninvasive ventilation time (IQR), days & $6(4-9)$ & $6(4-9)$ & $1.003(0.956-1.052)$ & 0.912 & & \\
\hline \multicolumn{7}{|l|}{ Enteral feeding type, $n(\%)$} \\
\hline Breast milk & $58(38.2)$ & $55(36.2)$ & Reference & 0.227 & & \\
\hline Formula milk & $46(30.3)$ & $32(21.1)$ & $1.363(0.761-2.441)$ & 0.297 & & \\
\hline Combination & $44(28.9)$ & $52(34.2)$ & $0.802(0.465-1.384)$ & 0.429 & & \\
\hline Achieved full enteral feeding, $n(\%)$ & $22(14.4)$ & $28(18.2)$ & $0.938(0.495-1.780)$ & 0.846 & & \\
\hline Median total parental feeding time (IQR), days & $9(7-11)$ & $8(5-10)$ & $1.102(1.010-1.202)$ & $0.029^{*}$ & $1.289(1.074-1.547)$ & $0.006^{*}$ \\
\hline \multicolumn{7}{|l|}{ Total time from birth (days), $n(\%)$} \\
\hline $0-5$ & $14(9.2)$ & $30(19.7)$ & Reference & 0.066 & & \\
\hline $5-10$ & $55(36.2)$ & $65(42.8)$ & $1.813(0.875-3.759)$ & 0.110 & & \\
\hline$>10$ & $26(17.1)$ & $20(13.2)$ & $2.786(1.177-6.593)$ & $0.020^{*}$ & & \\
\hline \multicolumn{7}{|l|}{ Medication, $n(\%)$} \\
\hline Inotropes & $6(3.9)$ & $16(10.5)$ & $0.188(0.048-0.728)$ & $0.016^{*}$ & & \\
\hline Antimycotics & $8(5.3)$ & & $0.791(0.211-2.972)$ & 0.729 & & \\
\hline \multicolumn{7}{|l|}{ Postpartum antibiotics administration (days), $n$ (\%) } \\
\hline None & $22(14.5)$ & $26(17.1)$ & Reference & 0.820 & & \\
\hline $1-3$ & $84(55.3)$ & $81(53.3)$ & $1.226(0.643-2.335)$ & 0.536 & & \\
\hline$>3$ & $46(30.3)$ & 45 (29.6) & $1.208(0.599-2.435)$ & 0.597 & & \\
\hline Antibiotic exposure (yes), $n(\%)$ & $138(90.8)$ & $143(94.1)$ & $0.620(0.260-1.480)$ & 0.282 & $0.078(0.007-0.879)$ & $0.039^{*}$ \\
\hline Median antibiotics time (IQR), days & $4(3-6)$ & $3(2-6)$ & $1.032(0.950-1.121)$ & 0.462 & & \\
\hline \multicolumn{7}{|l|}{ Antibiotic exposure per group, $n(\%)$} \\
\hline Aminoglycosides & $117(77.0)$ & $121(79.6)$ & $1.059(0.556-2.016)$ & 0.861 & & \\
\hline Carbapenems & $1(0.7)$ & $3(2.0)$ & $0.343(0.035-3.338)$ & 0.357 & & \\
\hline Cephalosporins & $23(15.1)$ & $38(25.0)$ & $0.558(0.312-0.998)$ & $0.049^{*}$ & & \\
\hline Glycopeptides & $18(11.8)$ & $19(12.5)$ & $0.987(0.494-1.971)$ & 0.970 & & \\
\hline Macrolides & $2(1.3)$ & 0 & NA & NA & & \\
\hline Oxazolidinones & 0 & 0 & $\mathrm{NA}$ & NA & & \\
\hline Penicillins (-clavulanic acid) & $132(86.8)$ & $138(90.8)$ & $0.957(0.301-3.040)$ & 0.940 & & \\
\hline Quinolones & 0 & 0 & NA & NA & & \\
\hline Rifampicin & 0 & 0 & $\mathrm{NA}$ & NA & & \\
\hline Trimethoprim-sulfamethoxazole & 0 & 0 & $\mathrm{NA}$ & NA & & \\
\hline Mortality, $n(\%)$ & $4(2.6)$ & $2(1.3)$ & $2.027(0.366-11.235)$ & 0.419 & & \\
\hline Median age at death (IQR), days & $16(6-25)$ & 15 (NA) & $1.018(0.811-1.278)$ & 0.878 & & \\
\hline Discharge before 28 days, $n$ (\%) & $55(36.2)$ & $50(32.9)$ & $1.157(0.721-1.857)$ & 0.547 & & \\
\hline Median age at discharge (IQR), days & $18(13-22)$ & $19(12-22)$ & $0.985(0.913-1.062)$ & 0.693 & & \\
\hline
\end{tabular}

LOS, late-onset sepsis; NA, not applicable; $\mathrm{T}_{0}$, clinical onset of sepsis; PPROM, preterm premature rupture of membranes; PDA, patent ductus arteriosus; RBC, red blood cells. ${ }^{1}$ Values are presented as OR (95\% CI). * Statistically significant difference.

risk factors per pathogen. So, this possible limitation may only account for CoNS-LOS cases. In the case of other pathogens, the course of sepsis is considered to be more fulminant.

In conclusion, since in the current study parenteral feeding was strongly associated with LOS development, it could be hypothesized that reduction of the number of parenteral feeding days might reduce the risk of LOS, which may be achieved by advancement of enteral feeding, preferably with breastmilk. Protective effects of early exposure to specific antibiotics underline the increasing notion that a disturbed microbial colonization may be involved in the pathophysiology of at least a selection of LOS cases. 
Table 5. Characteristics of infants with LOS caused by CoNS bacteria and matched controls in the period preceding LOS diagnosis ( $\mathrm{T}_{0}$ )

\begin{tabular}{|c|c|c|c|c|c|c|}
\hline & $\begin{array}{l}\text { LOS } \\
(n=111)\end{array}$ & $\begin{array}{l}\text { Non-LOS } \\
(n=111)\end{array}$ & Univariate analysis $^{1}$ & $p$ value & Multivariate analysis ${ }^{1}$ & $p$ value \\
\hline Median gestational age (IQR), weeks+days & $27+4(25+6-28+6)$ & $27+4(25+6-28+6)$ & $1.000(0.979-1.022)$ & 0.991 & & \\
\hline Median birth weight (IQR), g & $930(725-1,180)$ & $900(750-1,190)$ & $1.000(0.999-1.001)$ & 0.940 & & \\
\hline Male gender, $n(\%)$ & $61(55)$ & $54(48.6)$ & $1.288(0.760-2.183)$ & 0.347 & & \\
\hline Vaginal delivery, $n(\%)$ & $46(41.1)$ & $50(45.0)$ & $1.105(0.648-1.885)$ & 0.715 & & \\
\hline Multiple births, $n(\%)$ & $42(37.8)$ & $31(27.9)$ & $1.571(0.893-2.763)$ & 0.117 & & \\
\hline PPROM, $n(\%)$ & $32(28.8)$ & $27(24.3)$ & $1.312(0.720-2.390)$ & 0.375 & & \\
\hline Meconium-stained amniotic fluid, $n(\%)$ & $2(1.8)$ & $1(0.9)$ & $2.020(0.180-22.622)$ & 0.569 & & \\
\hline Median 1-min Apgar score (IQR) & $5(3-7)$ & $5(3-7)$ & $1.018(0.906-1.143)$ & 0.767 & & \\
\hline Median 5-min Apgar score (IQR) & $7(6-8)$ & $7(6-8)$ & $0.986(0.850-1.143)$ & 0.850 & & \\
\hline PDA, $n(\%)$ & $39(35.1)$ & $31(27.9)$ & $1.677(0.627-4.490)$ & 0.303 & & \\
\hline \multicolumn{7}{|l|}{ PDA treatment type, $n(\%)$} \\
\hline Ibuprofen & $36(32.4)$ & $30(27.0)$ & Reference & 1.000 & & \\
\hline Indomethacin & 0 & $1(0.9)$ & NA & 1.000 & & \\
\hline Surgical & $2(1.8)$ & 0 & NA & 0.999 & & \\
\hline Central line exposure, $n(\%)$ & $77(69.4)$ & $94(84.7)$ & $0.410(0.213-0.789)$ & $0.008^{*}$ & & \\
\hline Median central line time (IQR), days & $7(6-9)$ & $7(5-9)$ & $1.050(0.937-1.176)$ & 0.403 & & \\
\hline Central line exposure $48 \mathrm{~h}$ prior $\mathrm{T}_{0}, n(\%)$ & $62(55.9)$ & $78(70.3)$ & $0.535(0.308-0.931)$ & $0.027^{*}$ & & \\
\hline Peripheral line exposure, $n(\%)$ & $107(96.4)$ & $107(96.4)$ & $1.000(0.244-4.102)$ & 1.000 & $1.238(1.086-1.411)$ & $0.001^{*}$ \\
\hline Median peripheral line time (IQR), days & $6(4-9)$ & $6(4-8)$ & $1.060(0.981-1.146)$ & 0.142 & & \\
\hline Peripheral line exposure $48 \mathrm{~h}$ prior $\mathrm{T}_{0}, n(\%)$ & $89(80.2)$ & $77(69.4)$ & $1.786(0.964-3.311)$ & 0.065 & & \\
\hline Median RBC transfusions (IQR), $n$ & $2(1-3)$ & $1(1-2)$ & $1.217(0.836-1.770)$ & 0.305 & & \\
\hline Invasive ventilation exposure, $n(\%)$ & $54(48.6)$ & $64(57.7)$ & $0.696(0.410-1.181)$ & 0.179 & & \\
\hline Median invasive ventilation time (IQR), days & $4(3-8)$ & $5(2-9)$ & $1.012(0.918-1.117)$ & 0.804 & & \\
\hline Noninvasive ventilation exposure, $n(\%)$ & $103(92.8)$ & $96(86.5)$ & $2.012(0.816-4.958)$ & 0.129 & & \\
\hline Median noninvasive ventilation time (IQR), days & $6(4-9)$ & $6(4-8)$ & $0.996(0.928-1.070)$ & 0.922 & & \\
\hline \multicolumn{7}{|l|}{ Enteral feeding type, $n(\%)$} \\
\hline Breast milk & $35(31.5)$ & $37(33.3)$ & Reference & 0.171 & Reference & $0.019^{*}$ \\
\hline Formula milk & $38(34.2)$ & $23(20.7)$ & $1.747(0.873-3.496)$ & 0.115 & $3.779(1.257-11.363)$ & $0.018^{*}$ \\
\hline Combination & $37(33.3)$ & $41(36.9)$ & $0.954(0.502-1.811)$ & 0.954 & $0.782(0.328-1.865)$ & 0.580 \\
\hline Achievement of full enteral feeding & $22(14.4)$ & $28(18.2)$ & $0.938(0.495-1.780)$ & 0.846 & & \\
\hline Median total parental feeding time (IQR), days & $8(7-10)$ & $8(5-9)$ & $1.075(0.967-1.193)$ & 0.180 & & \\
\hline \multicolumn{7}{|l|}{ Total time from birth (days), $n(\%)$} \\
\hline $0-5$ & $8(7.2)$ & $23(20.7)$ & Reference & 0.122 & & \\
\hline $5-10$ & $34(30.6)$ & $44(39.6)$ & $2.222(0.885-5.578)$ & 0.089 & & \\
\hline$>10$ & $18(16.2)$ & $18(16.2)$ & $2.875(1.020-8.104)$ & $0.046^{*}$ & & \\
\hline \multicolumn{7}{|l|}{ Medication, $n(\%)$} \\
\hline Inotropes & $2(1.8)$ & $11(9.9)$ & $0.104(0.015-0.726)$ & $0.022^{*}$ & & \\
\hline Antimycotics & $3(2.7)$ & $5(4.5)$ & $0.382(0.069-2.125)$ & 0.272 & & \\
\hline \multicolumn{7}{|l|}{ Postpartum antibiotics administration (days), $n$ (\%) } \\
\hline None & $14(12.6)$ & $18(16.2)$ & Reference & 0.656 & & \\
\hline $1-3$ & $66(59.5)$ & $60(54.1)$ & $1.414(0.648-3.088)$ & 0.384 & & \\
\hline$>3$ & $31(27.9)$ & $33(29.7)$ & $1.208(0.515-2.865)$ & 0.665 & & \\
\hline Antibiotic exposure (yes), $n(\%)$ & $104(93.7)$ & $107(93.7)$ & $1.000(0.339-2.952)$ & 1.000 & $0.229(0.086-0.612)$ & $0.003^{*}$ \\
\hline Median antibiotics time (IQR), days & $4(3-6)$ & $3(2-6)$ & $1.043(0.932-1.167)$ & 0.460 & & \\
\hline \multicolumn{7}{|l|}{ Antibiotic exposure per group, $n(\%)$} \\
\hline Aminoglycosides & $92(82.9)$ & $89(80.2)$ & $1.504(0.661-3.418)$ & 0.330 & & \\
\hline Carbapenems & 0 & $3(2.7)$ & NA & NA & & \\
\hline Cephalosporins & $13(11.7)$ & $27(24.3)$ & $0.417(0.202-0.864)$ & $0.019^{*}$ & & \\
\hline Glycopeptides & $9(8.1)$ & $15(13.5)$ & $0.574(0.239-1.379)$ & 0.215 & & \\
\hline Macrolides & $1(0.9)$ & 0 & NA & $\mathrm{NA}$ & & \\
\hline Oxazolidinones & 0 & 0 & NA & NA & & \\
\hline Penicillins (-clavulanic acid) & $100(90.1)$ & $100(90.1)$ & $1.667(0.388-7.162)$ & 0.492 & & \\
\hline Quinolones & 0 & 0 & $\mathrm{NA}$ & NA & & \\
\hline Rifampicin & 0 & 0 & NA & NA & & \\
\hline Trimethoprim-sulfamethoxazole & 0 & 0 & NA & NA & & \\
\hline Mortality, $n(\%)$ & $1(0.9)$ & $2(1.8)$ & $0.495(0.044-5.544)$ & 0.569 & & \\
\hline Median age at death (IQR), days & 5 & 15 & NA & NA & & \\
\hline Discharge before 28 days, $n$ (\%) & $41(36.9)$ & $40(36.0)$ & $1.040(0.602-1.796)$ & 0.889 & & \\
\hline Median age at discharge (IQR), days & $18(13-21)$ & $19(12-22)$ & $0.989(0.909-1.077)$ & 0.807 & & \\
\hline
\end{tabular}

LOS, late-onset sepsis; NA, not applicable; $\mathrm{T}_{0}$, clinical onset of sepsis; PPROM, preterm premature rupture of membranes; PDA, patent ductus arteriosus; RBC, red blood cells. ${ }^{1}$ Values are presented as OR (95\% CI). * Statistically significant difference.

\section{Acknowledgement}

We thank Dr. Lissenberg-Witte for her excellent help with the statistical analysis and interpretation of the results.

\section{Statement of Ethics}

The local institutional review boards of all 9 participating centers granted approval (amendment A2016.363). The parents of all of the included infants gave written informed consent.

\section{Disclosure Statement}

The authors have no conflicts of interests to declare.

\section{Author Contributions}

Dr. el Manouni el Hassani conceptualized and designed this study, coordinated and supervised data collection, carried out the initial analyses, drafted the initial version of this paper, and reviewed and revised this paper. 
Dr. Berkhout, Dr. de Boer, and Dr. de Meij conceptualized and designed this study, coordinated and supervised data collection, and critically reviewed this paper for important intellectual content.

Dr. Mann designed the data collection instruments, collected data, and carried out the initial analyses.
Dr. Niemarkt, Dr. de Boode, Prof. Dr. Cossey, Dr. Hulzebos, Prof. Dr. van Kaam, Prof. Dr. Kramer, Dr. van Lingen, Prof. Dr. van Goudoever, Dr. Vijlbrief, Prof. Dr. van Weissenbruch, and Prof. Dr. Benninga critically reviewed this paper for important intellectual content.

\section{References}

1 Stoll BJ, Hansen N, Fanaroff AA, Wright LL, Carlo WA, Ehrenkranz RA, et al. Late-onset sepsis in very low birth weight neonates: the experience of the NICHD Neonatal Research Network. Pediatrics. 2002 Aug;110(2 Pt 1): 285-91.

2 Tsai MH, Hsu JF, Chu SM, Lien R, Huang HR, Chiang MC, et al. Incidence, clinical characteristics and risk factors for adverse outcome in neonates with late-onset sepsis. Pediatr Infect Dis J. 2014 Jan;33(1):e7-13.

3 Greenberg RG, Kandefer S, Do BT, Smith PB, Stoll BJ, Bell EF, et al.; Eunice Kennedy Shriver National Institute of Child Health and $\mathrm{Hu}$ man Development Neonatal Research Network. Late-onset Sepsis in Extremely Premature Infants: 2000-2011. Pediatr Infect Dis J. 2017 Aug;36(8):774-9.

4 Tröger B, Göpel W, Faust K, Müller T, Jorch G, Felderhoff-Müser U, et al.; German Neonatal Network. Risk for late-onset blood-culture proven sepsis in very-low-birth weight infants born small for gestational age: a large multicenter study from the German Neonatal Network. Pediatr Infect Dis J. 2014 Mar;33(3):238-43.

5 Stoll BJ, Hansen NI, Adams-Chapman I, Fanaroff AA, Hintz SR, Vohr B, et al.; National Institute of Child Health and Human Development Neonatal Research Network. Neurodevelopmental and growth impairment among extremely low-birth-weight infants with neonatal infection. JAMA. 2004 Nov; 292(19):2357-65.

6 Pammi M, Weisman LE. Late-onset sepsis in preterm infants: update on strategies for therapy and prevention. Expert Rev Anti Infect Ther. 2015 Apr;13(4):487-504.

7 Perlman SE, Saiman L, Larson EL. Risk factors for late-onset health care-associated bloodstream infections in patients in neonatal intensive care units. Am J Infect Control. 2007 Apr;35(3):177-82.

8 Patel AL, Johnson TJ, Engstrom JL, Fogg LF, Jegier BJ, Bigger HR, Meier PP. Impact of early human milk on sepsis and health-care costs in very low birth weight infants. J Perinatol. 2013;33:514-9.
9 Berkhout DJ, Benninga MA, van Stein RM, Brinkman P, Niemarkt HJ, de Boer NK, et al. Effects of Sampling Conditions and Environmental Factors on Fecal Volatile Organic Compound Analysis by an Electronic Nose Device. Sensors (Basel). 2016 Nov;16(11):1967.

10 Vermont Oxford Network. Vermont Oxford criteria: manual of operations. Part 2 - data definitions and infant data forms. Burlington: Vermont Oxford Network; 2018.

11 Cortez J, Makker K, Kraemer DF, Neu J, Sharma R, Hudak ML. Maternal milk feedings reduce sepsis, necrotizing enterocolitis and improve outcomes of premature infants. J Perinatol. 2018;38:71-4.

12 Oddy WH. The impact of breastmilk on infant and child health. Breastfeeding Rev. 2002;10:5-18.

13 Cristofalo EA, Schanler RJ, Blanco CL, Sullivan S, Trawoeger R, Kiechl-Kohlendorfer U, Dudell G, Rechtman DJ, Lee ML, Lucas A, Abrams S. Randomized trial of exclusive human milk versus preterm formula diets in extremely premature infants. J Pediatrics. 2013; 163:1592-95.e1591.

14 Berkhout DJ, Klaassen P, Niemarkt HJ, de Boode WP, Cossey V, van Goudoever JB, et al. Risk Factors for Necrotizing Enterocolitis: A Prospective Multicenter Case-Control Study. Neonatology. 2018;114(3):277-84.

15 Krishnamurthy S, Gupta P, Debnath S, Gomber S. Slow versus rapid enteral feeding advancement in preterm newborn infants 1000-1499 g: a randomized controlled trial. Acta Paediatr. 2010;99:42-46.

16 Becker K, Heilmann C, Peters G. Coagulasenegative staphylococci. Clin Microbiol Rev. 2014 Oct;27(4):870-926.

17 Hemels MA, van den Hoogen A, VerboonMaciolek MA, Fleer A, Krediet TG. A sevenyear survey of management of coagulase-negative staphylococcal sepsis in the neonatal intensive care unit: vancomycin may not be necessary as empiric therapy. Neonatology. 2011;100(2):180-5.
18 Tsai MH, Chu SM, Hsu JF, Lien R, Huang HR Chiang MC, et al. Risk factors and outcomes for multidrug-resistant Gram-negative bacteremia in the NICU. Pediatrics. 2014 Feb; 133(2):e322-9.

19 Madan JC, Salari RC, Saxena D, Davidson L, O’Toole GA, Moore JH, et al. Gut microbial colonisation in premature neonates predicts neonatal sepsis. Arch Dis Child Fetal Neonatal Ed. 2012 Nov;97(6):F456-62.

20 Mai V, Torrazza RM, Ukhanova M, Wang X, Sun Y, Li N, et al. Distortions in development of intestinal microbiota associated with late onset sepsis in preterm infants. PLoS One. 2013;8(1):e52876.

21 Fanos V, Cuzzolin L, Atzei A, Testa M. Antibiotics and antifungals in neonatal intensive care units: a review. J Chemother. $2007 \mathrm{Feb}$; 19(1):5-20.

22 Rao SC, Athalye-Jape GK, Deshpande GC, Simmer KN, Patole SK. Probiotic Supplementation and Late-Onset Sepsis in Preterm Infants: A Meta-analysis. Pediatrics. 2016 Mar; 137(3):e20153684

23 Garland JS, Alex CP, Sevallius JM, Murphy DM, Good MJ, Volberding AM, et al. Cohort study of the pathogenesis and molecular epidemiology of catheter-related bloodstream infection in neonates with peripherally inserted central venous catheters. Infect Control Hosp Epidemiol. 2008 Mar;29(3):243-9.

24 Downey LC, Smith PB, Benjamin DK Jr. Risk factors and prevention of late-onset sepsis in premature infants. Early Hum Dev. 2010 Jul; 86 Suppl 1:7-12.

25 Milstone AM, Reich NG, Advani S, Yuan G, Bryant K, Coffin SE, et al. Catheter dwell time and CLABSIs in neonates with PICCs: a multicenter cohort study. Pediatrics. 2013 Dec; 132(6):e1609-15

26 Sanderson E, Yeo KT, Wang AY, Callander I, Bajuk B, Bolisetty S, et al.; NICUS Network. Dwell time and risk of central-line-associated bloodstream infection in neonates. J Hosp Infect. 2017 Nov;97(3):267-74. 